\title{
The Baba Kiko LINE Sticker as a Creator's Virtual Representation
}

\author{
E Franzia ${ }^{1}$ \\ Faculty of Art and Design, Universitas Trisakti, Jakarta, Indonesia ${ }^{1}$ \\ \{eldafranzia@gmail.com $\left.{ }^{1}\right\}$
}

\begin{abstract}
The use of a mobile phone's instant messenger application is a new form of virtual community. As a digital society, it is melted in the global mediasphere. LINE is one of the instant messenger applications that contain many users in 19 languages from 230 nations all over the world (Beritasatu.com). The LINE sticker is one of the popular features among LINE users. The Baba Kiko LINE sticker is the object of the research. This sticker is designed by an independent creator from Indonesia and published in the LINE sticker shop. The Baba Kiko LINE sticker showed a unique character of women. This paper analyzed the meaning of the Baba Kiko LINE sticker as a virtual representation of the creator. The method used is the visual semiotic method including the syntactic dimension, semantic dimension, and pragmatic dimension. The result of this research is the understanding of mixed culture in the creator's background that affected the design of the Baba Kiko LINE sticker in the syntactic dimension, semantic dimension, and pragmatic dimension.
\end{abstract}

Keywords: Virtual, Representation, Character, LINE Sticker, Baba Kiko

\section{Introduction}

The development of communication technology and digital media is the basis of many instant messenger applications that are used in the daily communication of modern society. Each application has a different feature and a unique one for the users. One with many users in Indonesia is the LINE instant messenger. LINE was developed by NHN Corporation from Japan. First released in June 2011, LINE was used only in the iOS and Android operating systems at first, later integrating into the Blackberry and Windows Phone operating system. There are 101 million users of the LINE application from 230 countries in the world. LINE is the top position in the category of free applications in 42 countries, including Japan, Taiwan, Spain, Russia, Hong Kong, Thailand, Singapore, and Malaysia [1]. The LINE application underwent innovations to better engage their users by developing the LINE characters, namely Cony, Moon, Brown, and Sally. Those characters are primary characters in the LINE application. Besides the primary characters are also James, Boss, Jessica, and Choco. Choco is Brown's sister. Each character unique and contains different background stories. Those characters are the mascots of LINE that have been designed and packaged to interest and express the user's countenance in communication.

The LINE characters had published and promoted through LINE sticker. Users can download the LINE characters' sticker in the Sticker Shop. LINE stickers formerly only 
displayed the LINE characters, but after the users' growth, they also displayed other categories such as Disney characters, cartoon characters, anime, comedy, TV stars, etc. The LINE stickers vary between free and paid stickers. Sticker designs also vary from stickers made by the LINE application, sticker from LINE sticker design competition and also sticker designed by independent creators that made and sold the sticker design through the LINE application. The creator has the freedom to create the LINE sticker design. There are many kinds of LINE stickers designed by independent creators in the LINE store, one being the Baba Kiko LINE sticker, made by Rhea Bambulu, creator from Indonesia has a unique visual style and character representation. This paper analyses the visual style and the meaning of the Baba Kiko LINE sticker character as the creator's virtual representation. The method is a cultural study approach to understand human tendencies to form self-identity in cyberspace. The method of analysis is visual semiotics [2] to have an understanding of the creator's representation from the Baba Kiko LINE sticker.

\section{Literature review}

The openness of interaction in cyberspace has broadened the opportunity of an individual to seal their identity in the virtual world. Virtual identity is a personal identity in cyberspace. Through the internet, the user can adopt a different gender or sexual orientation according to their online persona [3]. Each individual has their own ability and freedom to create themselves in the virtual world. The creation is a personal representation in a certain role to interact in a virtual world. This virtual interaction is becoming self-definition and selfinvention [4]. Representation in cultural studies asks about how the world is socially constructed and represented to us and by us. According to Hall, there are two systems in the representation process. First, the mental representation system in the human mind, which is the relational concept of an object, human and event, which depends on concept formation and image that has formed in the human mind to represent the world. A mental representation system is not an individual concept system, but the organization and classification of various concepts and their relations. Second is the language system, as the meaning formation system to translate the concept into the language to become understandable to the human mind. The language system includes visual language and image [5]. Image is a self-representation identity; identity placed in relation to the context around self. Self-identity can only articulate through sets of personal representation [6]. A human is also a non-autonomous individual. Humans are formed in relation to a significant other who is the middle-ground between subject and value, meaning and cultural symbols in the world they live. Identity is becoming the cultural aspect of the acculturation process. Individuals learn from a significant other, through imitation and language in social life. This is a sociology review of the human subject. Humans are social creatures. The social aspect and individual impact on humans vice versa. The self is formed interactively between the inner world and the social world.

\section{Method}

The method used to understand the meaning of Baba Kiko LINE sticker as a creator's virtual representation is the visual semiotics method. Visual semiotics is one of the semiotic methods that are specifically focused on meaning through visual senses. The sign is a basic language element formed by signifier and signified element. The visual image is the signifier and the concept of meaning is the signified. According to Charles Morris, semiotic is 
classified into three dimensions, namely syntactic dimension, semantic dimension, and pragmatic dimension. The syntactic dimension includes the visual articulation system as language. The pictorial image is the grammatical language in a visual system. The image had seen assets of grammar in a language that give meaning through visual element within. A semantic dimension includes visual signs as an icon that has a visual similarity to signified, an index that leads toward signified or a symbol correlates to signified, according to Pierce. Pragmatic dimension includes image relation to use and function in the user's communication. Data collected in this research include visual data, reference and a questionnaire from the user. The method of collecting visual data is visual documentation from LINE application by screen capturing from LINE sticker shop. The data from the reference include books and references discussing LINE sticker. Data from the user were collected by direct interview with the Baba Kiko LINE sticker's creator to understand the design background and concept of meaning. The method of data analysis is in three phases, the syntactic meaning phase, semantic phase, and pragmatic phase. The syntactic meaning phase is the description of visual elements; the semantic phase is the description of use and function of the Baba Kiko LINE sticker for creator's representation, and the pragmatic phase is the creator's intention of meaning in conversation with Baba Kiko sticker.

\section{Results and discussions}

The Baba Kiko sticker is one of the LINE stickers created by Rhea Bambulu, an independent creator from Indonesia. This sticker was published in early 2017 through a sticker shop feature in the LINE application. The characters set in Baba Kiko sticker contain 32 image characters of Baba Kiko in various gestures and expressions. The character of Baba Kiko born in 2010, developed from the creator's childhood character. To understand the relation between Baba Kiko LINE sticker's characters to its meaning, the character is explained in the syntactic dimension, semantic dimension and pragmatic dimension.

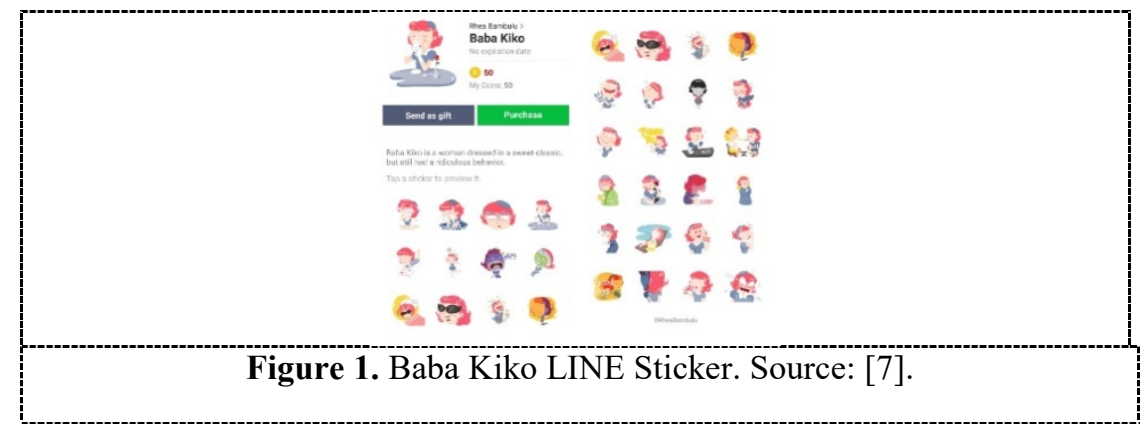

\subsection{Syntactic Dimension}

The line, shape, color, and typography are grammatical visual elements that formed the visual language of Baba Kiko LINE sticker character. The character of Baba Kiko is not defined by one or two main characters but by all sticker characters. Visual elements consist of the primary element and secondary elements. The primary elements are lines, forms, and colors that shaped the unity of Baba Kiko character's body. The secondary elements that support the main character's activity and expression are lines, forms, colors, and typography 
that shaped things as things that attached to the Baba Kiko character. Table 1 below explains the primary elements that shaped the full body of Baba Kiko.

Table 1.Visual Elements of The Baba Kiko Character

\begin{tabular}{llll}
\hline $\begin{array}{c}\text { Baba Kiko's } \\
\text { Character }\end{array}$ & \multicolumn{4}{c}{ Visual Elements } \\
\hline \multirow{2}{*}{ Body } & $\begin{array}{l}\text { Curve lines, no straight } \\
\text { line in the character's Slim } \\
\text { body }\end{array}$ & \multicolumn{1}{c}{ Form } & \multicolumn{1}{c}{ Colour } \\
Head & Curve lines & $\begin{array}{l}\text { Round head, short curly Peach face, red hair, red } \\
\text { hair, full rounded lips lips } \\
\text { Rounded collar dress, Blue dress with white } \\
\text { Fhite gloves, round hat, dots, white gloves, blue }\end{array}$ \\
& & $\begin{array}{l}\text { w's sunglasses, high hat, black sunglasses, } \\
\text { heels shoes }\end{array}$ \\
\hline
\end{tabular}

\subsection{Semantic Dimension}

The meaning of Baba Kiko's character in semantic dimension is a part or the whole visual that become the icon (it means has similarity image to the signified), or index (pointing towards the signified), or symbol (has meaning in relation to another signifier). According to Hall, representation has systemized by a relation between the creator and her concept of an object, human and event. The creator has been drawing the Baba Kiko character since her childhood. It was a visualization of a girl's unique personality. Creators had created the Baba Kiko character based on their favorite things in the self-stage of development. The name of Baba is an index to Baba Vanga, a Bulgarian blind clairvoyant, and herbalist. She is the creator's favorite clairvoyant because of her ability to predict the future. The name 'Kiko' is from a Japanese name, based on the creator's preference on Japanese culture. It influences the creator's choice on Baba Kiko's hair color. The hair color is pink, inspired by the character Black Lady, an antagonist character from Sailor Moon anime film. The Black Lady is visualized as a beautiful villain character because she was hypnotized by the King of Darkness. This character has become the creator's inspiration because it criticized social situation nowadays, which often judging a person from his/her appearance, in the creator's opinion.

The character of Baba Kiko is defined as a woman dressed in sweet-classic style but has silly behavior. Her style and expression are visualized in various gestures in Baba Kiko sticker character. The sweet-classic style is 50's fashion style. The characteristic is a one-piece dress in bright color, with a fitted top and a flared bottom skirt. For add-on accessories is a headpiece, small hat, ribbon or scarf, with gloves and sunglasses. The make-up is completed with red lipstick. The 50's fashion style is the creator's favorite style of fashion. According to the interview with the creator, she often wore this style on several occasions. Dress and accessories in Baba Kiko are the icons of the creator's style.

\subsection{Pragmatic Dimension}

Baba Kiko sticker image has a certain use and function for the user's communication. Each sticker character has meaning designed by the creator to express feelings and situations. The 
user is using a certain sticker to communicate a certain situation or feeling that can't be expressed verbally.

Table 2. Baba Kiko’s Expressions

\begin{tabular}{|c|c|c|}
\hline Baba Kiko's Character & Sticker Meaning & Pragmatic Dimension \\
\hline & Anger & $\begin{array}{l}\text { The user uses this sticker to express anger } \\
\text { to their opposite personalities. }\end{array}$ \\
\hline & Sad & $\begin{array}{l}\text { To show their sadness and condition of } \\
\text { breaking down to opposite person. }\end{array}$ \\
\hline
\end{tabular}

Table 2 above is the sample of Baba Kiko's expression in the Baba Kiko LINE sticker. The expression visualized is a different form of Baba Kiko's eye, eyebrow, mouth, and face's color. It symbolized the user's expressions when it uses in communication to the opposite person. Table 3 below is the sample of Baba Kiko's different situation visualized in Baba Kiko's LINE sticker. The user uses a certain sticker in communication to convey the message of the user's current situation to the opposite person. A specific situation is visualized through the property in the stickers. Baba Kiko's LINE sticker is used to exaggerate the feelings and conditions of the communicator to the opposite person. In many situations due to custom and habit in the Indonesia culture, one cannot speak in the straight word.

Table 3.Baba Kiko's Situations

\begin{tabular}{|c|c|c|}
\hline Baba Kiko's Character & Sticker Meaning & Pragmatic Dimension \\
\hline & Ill & $\begin{array}{l}\text { Users use this sticker to express their } \\
\text { ill condition to the opposite person. }\end{array}$ \\
\hline & Work & $\begin{array}{l}\text { To show their busy condition in } \\
\text { working situations to the opposite } \\
\text { person. }\end{array}$ \\
\hline
\end{tabular}

\section{Conclusion}

The Baba Kiko character is the self-representation of a creator that has an expressive characteristic and favors a certain fashion style. The creator's unique personality is also on the 
silly and goofy side, as opposed to figures that have a dark side and are often misunderstood by others. The Baba Kiko character is the self-expression of a creator that becomes her second-self. According to Nasrullah, creation is a personal representation in a certain role to interact in the virtual world. The virtual interaction is becoming a self-definition and selfinvention, birthed from her experience and knowledge in her relation to various cultures in her life. The creator's attachment to Western, Japanese, and Eastern Europe culture blended with the creator's base culture of Indonesian, which the communication process often includes nonverbal communication such as gestures and facial expressions. This LINE sticker is mediated on non-verbal communication. Instant messenger application users make up a virtual community or digital society that blends into a global society. The global society is a representation of pure and mixed local cultures. The mixed local culture is represented in a visual characteristic of the Baba Kiko LINE sticker. For the creator, the Baba Kiko LINE sticker comprises of the self-identity representation in the virtual world.

Acknowledgments. The author acknowledges the financial support provided by the Faculty of Art and Design, Trisakti University, through the research grant. The author also acknowledges the research material from Rhea Bambulu, the independent creator of the Baba Kiko LINE sticker.

\section{References}

[1] D. K. Salamoon, "Sticker LINE, Sebuah Jembatan Simbolik Teknologi Interaksi Manusia dalam Media," Komun. Nirmana, vol. 16, no. 1, pp. 12-17, 2017.

[2] K. Budiman, Semiotika Visual: Konsep, Isu, dan Problem Ikonositas. Yogyakarta: Jalasutra, 2011.

[3] N. Mirzoeff, An Introduction to Visual Culture. New York: Routledge, 2000.

[4] R. Nasrullah, Komunikasi Antarbudaya, Di Era Budaya Siber. Jakarta: Kencana Prenada Media Group, 2012.

[5] S. Hall, Representation, Cultural Representation and Signifying Practices. London: Sage Publication, 2012.

[6] T. Van Leeuwen and Carey Jewitt, Handbook of Visual Analysis. London: Sage Publication, 2001

[7] R. Bambulu, "Baba Kiko LINE Sticker," Line Store. [Online]. Available: https://store.line.me/stickershop/product/1373906/id. 